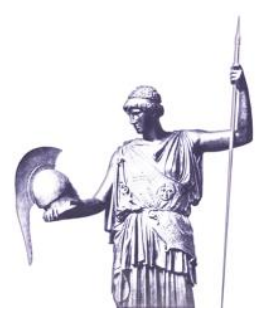

Connections: The Quarterly Journal

ISSN 1812-1098, e-ISSN 1812-2973

А.M. Ионеску, Connections QJ 15, № 2 (2016): 35-54

https://doi.org/10.11610/Connections.rus.15.2.03

Рецензированная статья

\title{
Нанотехнологии и глобальная безопасность
}

\section{Адриан М. Ионеску}

Ecole Polytechnique Fédérale de Lausanne, Switzerland, http://www.epfl.ch/index.en.html

\begin{abstract}
Резюме: Нанотехнологии дают возможность нахождения новых решений с многочисленными гражданскими и военными применениями. В этой работе представлено введение в нанотехнологии, рассматриваемые в качестве стратегической области исследований и производства, представлены тенденции, имеющие в потенциале ключевое влияние и рассмотрены связанные с этой проблематикой политика и последствия для безопасности. В качестве заключения, автор приводит некоторые соображения о политике в отношение применений нанотехнологий в сфере безопасности.
\end{abstract}

Ключевые слова: ключевая технология, кибер-физические системы, политика исследований, двойное назначение, превенция.

\section{Введение}

Термин нанотехнологии относится к созданию полезных материалов, устройств и систем путем манипулирования веществом в нанометровом (nm) масштабе, т.е. при размерах меньших, чем 100nm, и использования новых явлений и свойств, характерных для таких малых размеров. Чтобы понять вызовы, которые выдвигает перед технологиями и материалами такие масштабы размеров, на Фигуре 1 показаны несколько объектов, связанных с агрессивным уменьшением масштаба. К примеру, разве не удивительно то, что сегодняшние $14 \mathrm{~nm}$ металл-оксидные полупроводниковые полевые транзисторы (MOSFET) меньше, чем вирусы, и являются основой блока коммутирующих элементов для всей современной наноэлектроники, обеспечивающей высоко-производительные и мобильные вычисления. На деле, производство еще более миниатюрных и высокопроизводительных полупроводниковых устройств вошло в нанообласть еще в 2000 году с появлением технологии 90nm CMOS топологии, что иллюстрирует факт, что нано- 
электроника была одной из самих первых сфер, в которой начали использовать подход “системы атомов» для промышленных применений.

Еще более важным и удивительным для наноразмеров является то, что основные свойства макромасштабных материалов часто драматически изменяются при агрессивном уменьшении их размеров. Это касается характеристик их электрических, механических, оптических и химических свойств, которые меняются на порядок, что дало повод исследователям называть эти наноматериалы «чудо-материалами». ${ }^{1,2}$ Одномерные (1D) и двумерные (2D) материалы имеют относительно гораздо большую поверхность, чем та же масса материала в трехмерной макромасштабной форме, и при их электропроводимости гораздо сильнее проявляются квантовые эффекты. Их химическая активность так же изменяется. Многие из наномасштабных материалов (углеродные нанотрубки (УНТ), графен, оксиды металлов, нанокерамика и т.д.) приобретают гораздо более высокую механическую прочность, чем предполагают существующие модели материалознания для макроскопических масштабов. К примеру, модуль Юнга углеродных нанотрубок приближается к модулю бриллианта, а их теплопроводность выше на порядок. Причины всех этих драматических изменений лежат в мире квантовой физики. Понимание, моделирование и управление свойствами вещества на наноуровне с целью создавать новые наносистемы и наноматериалы с непревзойденными характеристиками является одним из главных вызовов перед наукой 21-го века. В целом, нанотехнологии можно рассматривать скорее как платформу базовых методов, ${ }^{3}$ чем как часть научной дисциплины или как технологию для получения материалов.

С другой стороны, поскольку нанотехнологии занимаются манипуляциями на атомном и молекулярном уровне, и созданием искусственных объектов с исключительными свойствами на размерном масштабе, невидимым для глаз человека, они становятся источником противоречий, в частности, в связи с их влиянием на сферы медицины и экологии. Научно-фантастические сценарии с самовозпроизводящимися наноботами, ${ }^{4}$ угрожающие человеческой жизни, и страхи, связанные с нанобиоинженерной едой (генетически модифицированной), создали некое изначально отрицательное восприятие нанотехнологий. С другой стороны, современные компьютерные и мобильные коммуникационные технологии уже используют нанотранзисторы и квантовые эффекты в кремниевых чипах, связанных с транс-

1 Возможно наиболее известным двухмерным «чудо» наноматериалом является графен, см. www.europarl.europa.eu/news/en/news-room/20150603ST062104/ Graphene-the-wonder-material-of-the-21st-century.

2 Andrea C. Ferrari, et al., "Science and Technology Roadmap for Graphene, Related Two-dimensional Crystals, and Hybrid Systems," Nanoscale 7:11 (2015): 4598-4810.

3 J. Whitman, "The arms Control Challenges of Nanotechnology," Contemporary Security Policy 32:1 (2011), 99-115.

4 Bill Joy, "Why the Future Doesn't Need Us," Wired, 1 April 2000, www.wired.com/ 2000/04/joy-2. 
портом и хранением зарядов для обработки информации во всех портативных устройствах, не являющихся никакой угрозой для потребителей. Напротив, потребители выигрывают от всех сервисов, обеспечиваемых нановычислениями.

В долгосрочном плане, настоящей перспективой нанотехнологий, как прогнозирует Рей Курцвейль, является то, что «мы сможем создавать почти все, что нам нужно в физическом мире из информационных файлов с использованием очень недорогостоящих исходных материалов». 5

Очевидно, что нано-технологии очень перспективны для применений в сфере безопасности, не сдерживаемые уже ограничениями традиционных технологий. Интересно, что рассматривая привилегированные направления исследований в нано-технологиях, связанных с защитой, выживанием и расширением возможностей человеческих органов чувств для солдата будущего, ${ }^{6}$ мы можем найти множество конверсионных применений для пожарников, полицейских и других аварийных служб и для гражданского общества в целом.

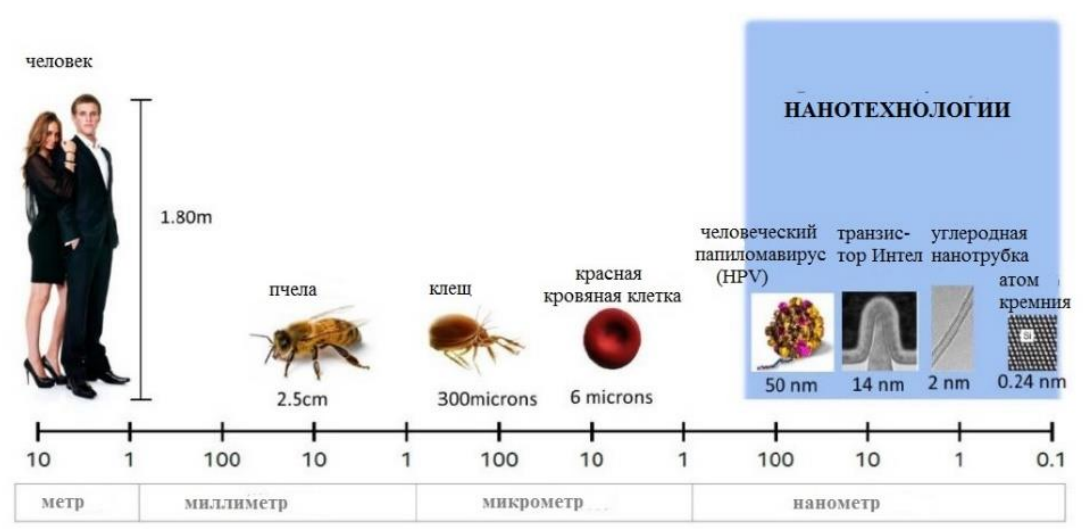

Фигура 1: Масштаб размеров от метра до нанометра: $14 \mathrm{~nm}$ транзистор Intel сегодня является наиболее ярким примером искусственного нано-объекта созданном человеком. ${ }^{7}$

5 "Ray Kurzweil on the Future of Nanotechnology," FUTURE TEK Science \& Technology News, 20 September 2011, http://www.futuretek.info/ray-kurzweil-on-the-future-ofnanotechnology/.

7 Intel, $14 \mathrm{~nm}$ Technology, www.intel.com/content/www/us/en/silicon-innovations/ intel-14nm-technology.html. 


\section{Нано-технологии как сфера стратегических исследований и} стратегического производства с точки зрения безопасности

Сейчас мир входит в новый этап развития информационных и коммуникационных технологий (ИКТ), который будет определять экономический рост и устойчивое развитие мира в следующие десятилетия. В будущем люди, системы и объекты будут взаимодействовать беспрепятственно друг с другом в сценариях Интернета вещей (ИВ). Можно полагать, что нанотехнологии будут ключевыми технологиями, позволяющими развитие будущих интеллигентных сенсорных систем и/или кибер-физических систем (КФС), ${ }^{8}$ которые в комплексе приведут к интегрированию функций регистрации параметров, вычисления, коммуникации и менеджмента энергии. Нанотехнологии определенно являются следующей промышленной революцией и можно ожидать, что они напрямую окажут влияние на ежедневную жизнь и приведут к огромным и беспрецедентным улучшениям в следующих областях общественной и экономической жизни:

- Эфрфективные энергетические технологии во всех формах, начиная от энергетически эффективных сенсорных систем для мониторинга человеческого тела и зданий как части концепций умных городов ${ }^{9}$ и еще более умной планеты ${ }^{10}$ и до энергетически эффективных высокопроизводительных вычислений в центрах для данных. Существенным для достижения этой цели является внимательный выбор базовых нано-технологий, которые смогут уменьшить потребление энергии на один вычисляемый, передаваемый и измеряемый бит, в сочетании на системном уровне с новым поколением перезаряжаемых батарей, устройств для хранения и поглощения энергии.

- Новые недорогие технологии для изготовления и массового производства являются одной из наиболее интересных сфер использования нано-технологий, применяющих производственный процесс «снизувверх», и использования новых нано-материалов (нано-волокон, нанотрубок, нано-частиц) независимым способом или в сочетании с существующими материалами для создания объектов с уникальными свойствами и характеристиками.

- Усовершенствованные и устойчивые решения в сфере наноздоровья и долгожительства в сочетании с новым качеством жизни.

8 Кибер-физической системой (КФС) называется система взаимодействующих вычислительных элементов, контролирующих физические объекты; они могут быть запроектированы как сети взаимодействующих элементов с физическими входами и выходами и полагается, что они будут обеспечивать работу будущей критической инфраструктуры, формируя основу новых и будущих интеллигентных сервисов.

9 https://ec.europa.eu/digital-agenda/en/smart-cities.

10 http://www-03.ibm.com/ibm/history/ibm100/us/en/icons/smarterplanet/. 
- Интеллигентный транспорт, включая электрические автомобили, морские суда, железные дороги и интеллигентная инфраструктура, а также взаимодействия типа «узел-узел».

- Улучшенная надежность, конфиденциальность и безопасность.

- Оздоровление и сохранение окружающей среды и уменьшение углеродных эмиссий в результате развития, инновационные решения для улучшения качества воды и воздуха.

- Расширение границ космических исследований.

- образование, которое будет объектом драматического изменения парадигм как в смысле формы (новые способы преподавания содержания), так и смысле в способе предоставления (удаленное предоставление знаний и улучшение образования в течение всей жизни).

- Обеспечение всем доступа к ИКТ в глобальном масштабе и содействие распространению демократии и глобализации в целом.

Следовательно, нанотехнологии становятся стратегической сферой инвестиций, которой не может пренебрегать ни одна страна и ни одна нация. Области их влияния более многочисленны, чем ожидалось в результате прорывов в области обработки информации (связанные с высокопроизводительными и широко распространенными вычислениями) и медицине.

Нано-технологическая революция определенно окажет влияние как на гражданские, так и на военные применения, которые уже нельзя рассматривать изолированно, и определенно столкнется с большим противодействием и с большими рисками. С социальной точки зрения, когда рассматриваются последствия нано-технологий для конфиденциальности, безопасности и человеческих прав, проблема становится еще более сложной, поскольку она касается широкого спектра новых областей, в том числе наноизготовление, наносборка, информационные технологии (в том числе наноэлектронные системы и ИВ), нано-биотехнологии, нано-фармацевтика и нано-терапия.

Поскольку нано-технологии являются все еще новой сферой, международные сообщества и нации все еще могут формировать наилучшую траекторию развития нано-технологий и избежать все возможные недобронамеренные применения, особенно в сфере национальной и международной безопасности. Надо добиться полного понимания проистекающих из этого вызовов путем привлечения к активному участию научного общества для объективной оценки как позитивного потенциала нано-технологий, так и необходимых регуляций для предотвращения связанных с ними рисков. Для государственных структур важно полностью понимать важность и последствия нано-технологий для экономики, общества, безопасности и вооруженных сил и полностью использовать их потенциал, основываясь на превентивных стратегиях, применяемых на всех уровнях. 


\section{Тенденции в нанотехнологиях: настоящее и будущее}

Несмотря на огромный прогресс в последнее время, нанотехнологии все еще выходят из детского возраста, и эксперты все еще далеки от полного использования их ожидаемых экономических и социальных преимуществ. В этом разделе обсуждаются сферы, в которых технический прогресс в области нанотехнологий ясно связан с новыми применениями и сервисами, хотя их будущее, возможно, окажется совершенно отличным.

\section{Наноматериалы}

Это один из наиболее широких сегментов с критически важной ролью для будущих применений нанотехнологий. "Наноматериалом» называется вещество, в котором хотя бы одно измерение находится в диапазоне 0.1$100 \mathrm{~nm}$ : нанозерна с размером меньше, чем в $100 \mathrm{~nm}$, нанонити, нанотрубки или нановолокна с диаметром меньше, чем $100 \mathrm{~nm}$, нанопленки с толщиной меньше, чем в 100nm; при таких размерах материалы имеют существенно улучшенное поведение и улучшенные свойства. Существует множество наноматериалов с самыми разнообразными применениями, и их категоризация является относительно сложным вопросом. Однако, в последние десять лет особое внимание обращалось на следующие 12 категорий: (1) наноструктурные материалы, (2) наночастицы и нанокомпозиты, (3) нанокапсулы, (4) пористые наноматериалы, (5) нановолокна, (6) фуллерены, (7) нанопроволоки, (8) однослойные и многослойные (углеродные) нанотрубки, (9) дендримеры, (10) молекулярная электроника, (11) квантовые точки и (12) ультратонкие пленки. В смысле одновременного улучшения характеристик и уменьшения масштабов от органически присущих наноматериалам свойств выигрывают электронные, механические и оптические устройства.

\section{Экзафлопсный энергоэффективный компьютинг}

Основные инициативы по развитию научного компьютинга направлены на создание экзафлопсных суперкомпьютеров. В Соединенных Штатах Национальная Стратегическая Инициатива по Компьютингу (НСИК) поставила жесткое требование достичь невероятно высокого уровня производительности и энергоэффективности суперкомпьютеров. Такие экзафлопсные суперкомпьютеры будут примерно в 30 раз более мощными, чем наиболее быстрые сегодняшние машины, и их графические процессоры будут в состоянии делать в десять раз больше операций на единицу расходованной энергии по сравнению с современными компьютерами. Поэтому в настоящее время уделяется много внимания изучению новых энергоэффективных нанотехнологий, позволяющих обеспечить вышеупомянутые производительность и энергоэффективность. Экзафлопсные компьютеры располагают потенциалом обеспечить беспрецедентные прорывы в таких областях, как персонализированная медицина, понимание человеческого мозга, прогнозирование климата, 
экономические модели и критические проблемы безопасности. Что касается безопасности, многие эксперты считают, что оборонный потенциал и стратегия любой страны будут в большой степени зависеть от ее вычислительных возможностей.

\section{Наносенсоры, умные носимые устройства и Интернет вещей}

Сфера наносенсоров является одной из нескольких областей, которые напрямую и всеохватно используют преимущества нанотехнологий, так как ультрамалые размеры этих устройств делают их очень подходящими для обнаружения исключительно малых концентраций газов или частиц любого типа, доводя их чувствительность до теоретических границ. Более того, нанофункционализация поверхностей может решить основные проблемы селективности датчиков и обмена информации между ними, а также сделать сенсорные поверхности самоочищающимися или самоприкрепляющимися. У наносенсоров настолько малое потребление энергии, что они могут получать питание из солнечных панелей, термоэлектрических генераторов или из преобразователей кинетической энергии, их энергоэффективность делает их подходящими для любых автономных будущих систем с датчиками. Более того, большинство нанодатчиков можно использовать на передовых наноэлектронных платформах, на которых уже есть наноустройства размером меньше, чем в $22 \mathrm{~nm}$, что просто означает, что есть высокий уровень технологической готовности (УТГ) для использования нанодатчиков любого вида, хотя для промышленных применений все еще есть различия в степени их технологической зрелости. Недавно были предложены и продемонстрированы такие сенсоры, базированные на конвергенции вычислительных и сенсорных платформ. ${ }^{11}$ Такие приложения в сфере безопасности, как электронные носы, нанобиосенсоры и все виды датчиков для мониторинга окружающей среды будут иметь большую пользу от развития наносенсоров. Сегодня датчики являются ключевыми компонентами и определяющими факторами в любом комплексном сценарии, в котором имеют место расширенные в реальном времени человеческие ощущения как для гражданских, так и для военных приложений.

Флагманским проектом технологий будущего с наименованием Ангелыхранители для более умной жизни (проект AX) были предложены передовые концепции, связанные с носимыми на себе реализациями. ${ }^{12}$ Речь идет о квазиневидимых, с нулевым энергопотреблением сетей датчиков на поверхности человеческого тела, или, если это необходимо, имплантированных устройств, осуществляющих мониторинг жизненных функций и дающих необходимую информацию для предприятия соответствующих действий для сохранения человеческой жизни. Они будут получать четкую картину состояния здоровья данного лица, адаптированную к индивидуальным по-

11 Sara Rigante, et al., "Sensing with Advanced Computing Technology: Fin Field-Effect Transistors with High-K Gate Stack on Bulk Silicon," ACS Nano 9/5 (2015): 4872-4881.

12 http://www.ga-project.eu. 
требностям, используя работающую в реальном времени, с ультранизким энергопотреблением, мультипараметрическую комбинацию неинвазивных, биосигнальных сенсоров (ЭКГ, акселерометры, гироскопы, пульсоксиметры и т.д.) для раннего предупреждения, и таким образом, улучшения качества жизни. В таких системах могут применяться такие новые технологии, как электронная кожа или носимые на себе самоподпитывающиеся системы датчиков с беспроводным интерфейсом. Такие системы будут совместимыми, с коммуникационной точки зрения, с любыми существующими шлюзами связи (смартфоны и умные часы), и смогут функционировать как умные элементы будущего ИВ.

Более усовершенствованные версии таких умных систем, предложенных проектом AX, в Европе могли бы защищать людей от разнообразных экологических опасностей, в том числе связанных с выбросами вредных веществ и с катастрофами, делая окружающую среду более безопасной. Предполагается, что такие устройства будут давать доступ в режиме реального времени к дополненной реальности, в том числе предупреждения о таких опасностях, как электромагнитное или ионизирующее излучение, чрезмерное подвергание УВ, высокая концентрация аллергенов, цветочной пыльцы и вредных газов. Они будут построены на комплексных, энергоэффективных коммуникационных технологиях, базирующихся на новых наноматериалах, предоставляя возможности для полностью сетевой работы. Можно ожидать множество экологических применений, как например умные сопровождающие устройства для внутреннего и внешнего использования с шестью органами чувств, контролирующими качество воды и воздуха, а также надежные персональные устройства для комплексного менеджмента при чрезвычайных ситуациях.

\section{Сбор, сохранение и менеджмент энергии для умных (микро/нано) cucmem}

Нанотехнологии могут ответить на фундаментальные вызовы, связанные с конвертированием разных видов энергии, встречающихся в окружающей среде (солнечной, термальной, химической и механической) в электрическую энергию, и эффективным сохранением и менеджментом конвертированной энергии для энергоснабжения будущих автономных систем. По мнению $\mathrm{AX}$, солнечные элементы могли бы превысить максимальный порог коэффициента полезного действия с помощью новой архитектуры наноустройств и новых наноматериалов (например, с использованием генерирования множества экситонов). В сфере термальных сборщиков энергии, работающих при комнатной температуре, возможно создание термоэлектрических малоразмерных устройств с термоэлектрической эффективностью ZT, существенно большей, чем 1, с использованием наноструктурных материалов, основанных на технологиях гибких материалов, интеграции суперрешеток и структур квантовых точек. Тонкие и широкополосные нанорезонаторы, организованные в матрицах, могли бы увеличить выход мощ- 
ности для сборщиков механической энергии. При сохраняющих энергию электродных устройствах с большой поверхностью (наноборозды, наностолбики, углеродные нанотрубки и графен) полностью будет использоваться высокая проводимость 2D и 1D наноструктур.

\section{Аутентификация}

Аутентификация является критически важным элементом сетевой безопасности и, несомненно, на нее окажет влияние развитие нанотехнологий. Одним из ожидаемых результатов этого развития является улучшение правильности аутентификации. Хотя нанооптику считают потенциально наиболее подходящей для совершенных с точки зрения безопасности методов аутентификации, с развитием нанотехнологических многопараметрических сенсоров, процесс аутентификации в будущем может включать использование усовершенствованных кодов доступа, основанных на индивидуализированных многопараметрических технологиях, в том числе биологические сигналы, которые было бы сложно воспроизвести.

\section{Квантовая криптография}

Сегодняшние криптографические алгоритмы основываются на шифровании с помощью ключа и других алгоритмов, которые считаются достаточно надежными. В то же время, квантовые компьютеры базируются на кубитах и требуют обработки информации на атомном уровне, новой технологии, в развитии которой в последние десять лет имеется существенный прогресс. Эти компьютеры не заменят традиционных компьютеров во всех сферах компьютинга, но они предоставляют фантастические возможности для комплексного распознавания образов и инновационных непробиваемых методов шифрования. Если квантовый компьютинг станет реальностью, он перестроит и драматически изменит все нынешние криптографические системы. Однако, существует большая опасность, что квантовый компьютинг можно будет использовать для разбивания сегодняшних стратегий безопасности путем реверсивного вычисления персональных ключей со скоростью, намного превышающей скорость конвенциональных компьютеров. К примеру, считается, что 2048-битовые RSA ключи можно было бы разбить на квантовом компьютере с 4000 кубитами и 100 миллионами входов.

Похоже, что разведывательные ведомства очень интересуются этим вопросом, и недавно Агентство национальной безопасности США (АНБ) раскрыло свой интерес к переходу на квантово-устойчивые протоколы. Служба разведки и безопасности Дании выделила другой вид важной угрозы в сценарии, названном "перехватывай сейчас, расшифровывай потом», ${ }^{13}$ при котором атакующий мог бы начать перехват и накапливание финансовых транзакций или другого чувствительного зашифрованного трафика и осуществлять расшифровку позже, когда будут в наличности квантовые компь-

${ }^{13}$ Chris Cesare, "Online Security Braces for Quantum Revolution," Nature 525 (8 September 2015): 167-168. 
ютеры. Эта сфера еще более связана с нанотехнологиями с учетом недавнего прогресса в области все более успешного применения кубитов в кремниевых нанотехнологиях, ${ }^{14}$ позволяющих апскейлинг квантовых компьютеров и доведение их до работоспособности в рамках 20 лет.

\section{Регенеративная медицина и молекулярный инжиниринг}

Одной из главных целей мультидисциплинарных работ, связанных с регенеративной медициной, является создание биомиметических наномасштабных основ для восстановления и замещения поврежденных биотканей. Источники стволовых клеток и биосигналы стали золотым стандартом для инжиниринга тканей, тогда как использование микро-нанопроизводственных технологий для генерирования основ для направления адгезии, распространения, дифференциации и миграции стволовых/ прогениторных клеток является новой областью в инжиниринге тканей и регенеративной медицине. Один из ее ключевых аспектов касается факта, что «понимание взаимодействия наноматериалов со ствольными клетками может дать знания, применимые к комбинациям клетки-основы в инжиниринге тканей и регенеративной медицине». ${ }^{15}$ Поэтому текущим вызовом является дизайн надежных основ с низкой токсичностью, контролирующих 2D поверхности для клеточной адгезии и ассемблирования в 3D структуры. В будущем ожидается, что сочетания совершенных наноматериалов с протогениторными или стволовыми клетками и соответствующими биологическими сигналами обеспечат дальнейшие возможности для осуществления полностью регенеративной наномедицины.

Предотвращающая старение терапия и доставка лекарственных препаратов включают молекулярный инжиниринг и введение наномасштабных машин в кровоток для нахождения и восстановления или уничтожения раковых клеток или для лечения других патологий. Лечение рака является ключевой областью, в которой ожидаются прорывные решения, основанные на наночастицах, которые можно направлять для уникального таргетирования раковых клеток путем встраивания доставщиков наноагентов или механизмов других типов для уничтожения раковых клеток. Ожидается, что в будущем такие нанотерапии заменят сильно агрессивные химио- и радиотерапии.

Не делая никаких спекуляций относительно какого-либо значительного увеличения продолжительности жизни человека благодаря нанотерапии, которое невозможно представить себе сегодня (более 200 лет или что-то такого порядка), и которое часто рассматривается как шаг к бессмертию, есть основательная надежда, что нанотехнологии дадут по-настоящему ре-

14 Menno Veldhorst et al., "A Two-qubit Logic Gate in Silicon," Nature 526 (15 October 2015): 410-414.

15 King-Chuen Wu et al., "Nanotechnology in the Regulation of Stem Cell Behavior," Science and Technology of Advanced Materials 14 (2013) 054401, doi: 10.1088/1468$6996 / 14 / 5 / 054401$. 
генеративные подходы для лечения тканей и органов, открывая новые пути для медицины будущего.

\section{Производственные наноинструменты с атомарной точностью}

Ожидается, что прогресс нанотехнологий откроет пути к так называемому атомарно точному производству (АТП) и атомарно точным производственным наносистемам (АТПН). Сегодня существующие прототипные сканирующие контактно-измерительные АТП системы оцениваются в исследовательских лабораториях, где они используются для прототипирования и изучения наноустройств и нанообъектов. Полупроводниковая промышленность уже располагает технологическими средствами для создания ультрачистых, тонкослойных материалов, необходимых наноэлектронике (например, инструменты для отложения атомарных слоев). Наномасштабные АТПН исходят непосредственно из природы и могут производить уникально сложные наноструктуры с атомарной точностью в огромных количествах. Важно отметить, что эта область имеет огромное значение как для органического, так и для неорганического производства, причем многие из этих производственных инструментов сначала создавались для биоинжиниринга.

\section{Дорожные карты нанотехнологий}

Европа и Соединенные Штаты являются ключевыми субъектами при создании дорожных карт и координации приоритетов для основных инвестиций в эту сферу. Финансирование военных нанотехнологий составляет существенную долю от общего финансирования в Соединенных Штатах, которые являются лидером в этой области и занимаются нанотехнологиями с 1980-х. Более того, в 1996 году нанотехнологии были определены как одно из шести стратегических для обороны США исследовательских направлений. Соответственно, от 25 до 30 процентов от финансирования Национальной нанотехнологической инициативы шло в Министерство обороны (МО) США. В США военные исследования и разработки в области нанотехнологий сфокусированы на развитии миниатюрных датчиков, высокоскоростной обработки информации, беспилотных боевых транспортных платформ, улучшенной практической подготовки в среде виртуальной реальности и повышении работоспособности человека.

В Европе, наоборот, фокус лежит на гражданских применениях нанотехнологий, и в последнем докладе инициативы NANOfutures предлагается основанная на цепочке добавленной стоимости дорожная карта для развития нанотехнологий, в которой семь нанотехнологических векторов связаны с разнообразными сферами приложений, в которых спрогнозировано промышленное и экономическое влияние нанотехнологий. ${ }^{16}$ Каждый из этих

16 Integrated Research and Industrial Roadmap for European Nanotechnology (Nanofutures, 2012), www.nanofutures.eu/sites/default/files/NANOfutures_Roadmap\%20 july\%202012_0.pdf. 
векторов имеет соответствующее многосекторное влияние в разные моменты времени. Целостная картина представлена на Фигуре 2. В этом докладе предлагается, чтобы субъекты, принимающие политические и экономические решения, предприняли действия в ответ на потребности промышленности и вызовы в сфере исследований и инноваций для успешного развития безопасных и надежных нанопродуктов. В докладе содержатся многочисленные примеры, указаны потенциальные ведущие рынки и социальные вызовы, которые можно разрешить с помощью рынков нанотехнологий, которые стали основой планов финансирования по Европейской программе Горизонт 2020. Так называемое инклюзивное, инновационное и безопасное общество является частью больших социальных вызовов в этой концептуальной дорожной карте.

В США Институт перспективных нанотехнологий, финансируемый Семейным фондом Уэйт и корпорацией Sun Microsystems, и с помощью мультидисциплинарной группы ученых и инженеров создали другую нанотехнологическую дорожную карту. ${ }^{17}$ Их концепция широкомасштабна, включает применения в медицине, биомедицине, новые поколения датчиков, компьютерные технологии, дисплейные и осветительные системы. Особое внимание обращено на молекулярную нанотехнологию. В этой дорожной карте содержится интересная категоризация и обсуждение различных нанотехнологических домейнов на трех временных горизонтах.

Существует, между прочим, Нанотехнологическая дорожная карта NASA, которая очень подробна и разделена на четыре основных сектора в Структуре деления технологических областей (СДТО) для нанотехнологий, все из которых связаны с современной конкретикой и вызовами космических исследований:

i. Искусственные материалы и структуры, разделенные на: (а) легкие структуры, касающиеся наноматериалов для легких, устойчивых структурных систем и высокоэффективных кабелей для передачи данных, проводки и устройств, (б) устойчивые к повреждениям системы, усиление робастности систем через усовершенствование межслойных интерфейсов, мониторинг здоровья и встроенные ремонтные механизмы, (в) покрытия из очень тонких, искусственных поверхностных барьеров, которые обеспечивают защиту от экологических опасностей и термический менеджмент, (г) нано-адгезивы для космической сборки и (д) тепловая защита и контроль в экстремальных условиях.

ii. Хранение, генерирование и распределение энергии, который использует преимущества процессов, происходящих на молекулярном и атомарном уровне для увеличения эффективности хранения, генерирова-

17 "How Close Are We to Real Nanotechnology?" Humanity+, June 1, 2009, http://hplusmagazine.com/2009/06/01/how-close-are-we-real-nanotechnology. 


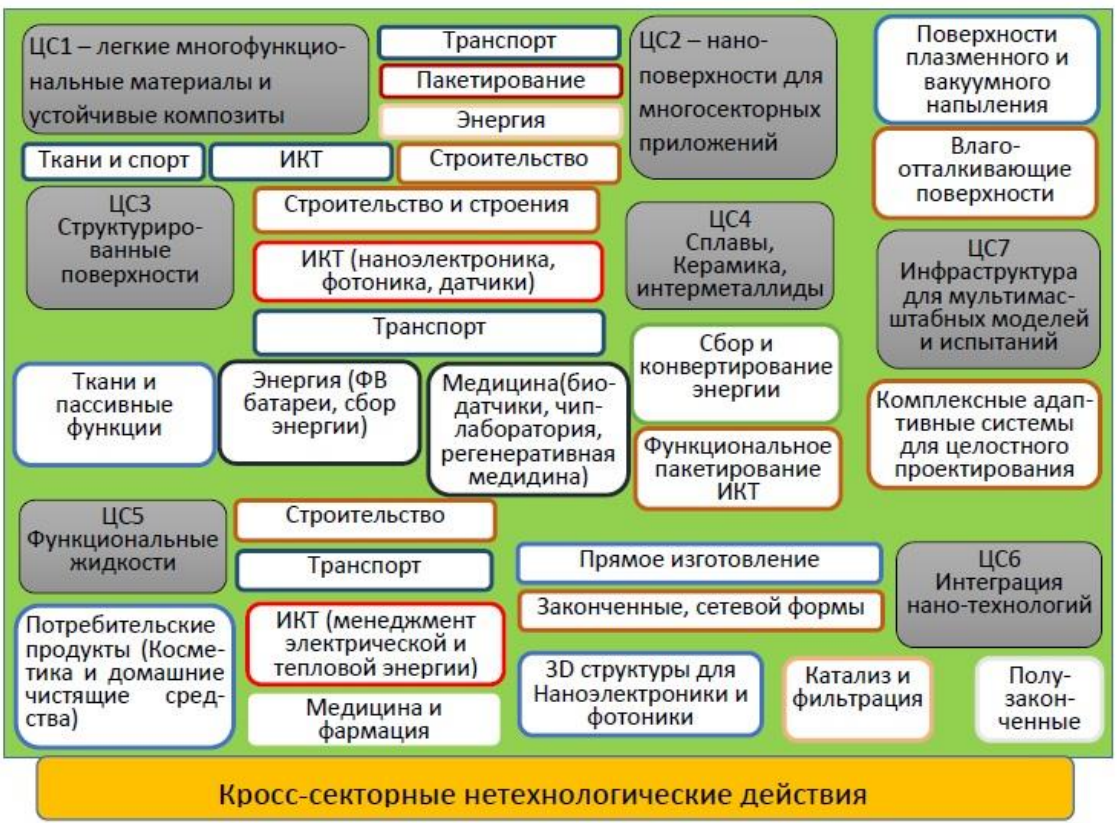

(a)

\begin{tabular}{|c|c|}
\hline \multicolumn{2}{|r|}{ Основные социальные вывовы по рынкам } \\
\hline ЭНЕРГИЯ & $\begin{array}{l}\text { - Безопасная, чистая и эффективная энергия } \\
\text { - Умный, зеленый и интегрированный транспорт } \\
\text { - Климит, эффективность ресурсов и сырье }\end{array}$ \\
\hline TPAHCПOPT & $\begin{array}{l}\text { - Умный, зеленый и интегрированный транспорт } \\
\text { - Климат, эффективность ресурсов и сырье }\end{array}$ \\
\hline $\begin{array}{l}\text { СТРОИТЕЛЬСТВО И } \\
\text { СТРОЕНИЯ }\end{array}$ & $\begin{array}{l}\text { - Безопасная, чистая и эффективная энергия } \\
\text { - Климмат, эффективность ресурсов и сырье }\end{array}$ \\
\hline $\begin{array}{l}\text { МЕДИЦИНА И } \\
\text { ФАРМАЦИЯ }\end{array}$ & - Здоровье, демографические изменения и благосостояние \\
\hline ИКT & $\begin{array}{l}\text { - Здоровье, демографические изменения и благосостояние } \\
\text { - Инклюзивное, инновационное и безопасное } \\
\text { общество }\end{array}$ \\
\hline МАТЕРИИ И СПОРТ & $\begin{array}{l}\text { - Здоровье, демографические изменения и благосостояние } \\
\text { - Инклюзивное, инновационное и безопасное общество }\end{array}$ \\
\hline $\begin{array}{l}\text { ПОТРЕБИТЕЛЬСКИЕ } \\
\text { ТОВАРЫ }\end{array}$ & - Здоровье, демографические изменения и благосостояние \\
\hline ПАКЕТИРОВАНИЕ & $\begin{array}{l}\text { - Здоровье, демографические изменения и благосостояние } \\
\text { - Продовольственная безопасность } \\
\text { - Климат, зффективность ресурсов и сырье }\end{array}$ \\
\hline
\end{tabular}

(б)

Фигура 2: (а) Цепочки добавленной стоимости для нанотехнологий и (б) основные социальные вызовы для разных рынков, согласно Nanofutures. ${ }^{11}$ 
ния и распределения энергии. Ожидается, что батареи и суперконденсаторы с высокой плотностью энергии и мощности, в которых используются наноматериалы, будут обеспечивать надежное функционирование менеджмента энергии в тяжелых условиях (экстремальных температурах, радиации, химически активной атмосфере).

iii. Силовые установки являются критически важными для обеспечения движущей силы в космосе, и NASA изучает ракетные топлива на основе наночастиц с улучшенной мощностью, теплопроводностью и надежностью для более легких, эффективных и долговечных систем силовых установок для космических и земных летательных аппаратов.

iv. $\quad$ датчикам, электронике и устройствам в данной сфере предъявляются особые требования, в частности касающиеся улучшенных характеристик, более низкого энергопотребления, компактности и радиационной устойчивости. Эти требования применимы и к наноэлектронике, наносенсорам, нано силовым приводам и разным видам наноинструментов. $^{18}$

Надо отметить, что многие из требований, предъявляемых к технике для космических исследований, применимы и к военным приложениям, поскольку военная техника может располагаться и в космосе. В прошлом исключительно жесткие спецификации космических программ и авиационных приложений привели к огромному прогрессу в гражданских приложениях и к технологическим прорывам; это может быть связано с фактом, что в этой области показатели работоспособности и надежности преобладают над требованиями к цене, поскольку здесь прогресс осуществляется путем нахождения решений проблем, в отличие от других областей.

Обобщение всех этих тенденций в общую концепцию унифицированной дорожной карты для развития нанотехнологий с ударением на реализациях в сфере безопасности является сложной задачей, учитывая большое разнообразие нанотехнологических областей, приложений и состояний зрелости. На Фигуре 3 показан один возможный сценарий, в котором прогнозируется наличие трех основных сценариев для основанной на нанотехнологиях безопасности.

Горизонт I включает цифровую и обеспечиваемую наносенсорными технологиями безопасность. Технологии компьютинга уже вошли в эпоху нанотехнологий, и можно ожидать, что они дадут исключительно высокую вычислительную мощность как мобильным компьютерам, так и суперкомпьютерам со стационарной инфраструктурой, когда достигнут суб-7nm порог для транзисторных затворов на передовых кремниевых CMOS платформах и при создании энергоэффективных устройств и системных архитектур. На основе подобных платформ функциональная диверсификация в смысле мультипараметрических нано-сенсоров и нано-оптических функций даст

18 NASA Technology Roadmaps - TA 10: Nanotechnology (NASA, May 2015), www.lpi.usra.edu/sbag/goals/capability_inputs/2015_Tech_10_nanotechnology.pdf. 
толчок технологиям аутентификации и раннему обнаружению любых внешних рисков и опасностей в гражданском обществе и в военной среде. Объекты ежедневного пользования можно будет оборудовать носимыми физическими, физиологическими и экологическими датчиками, которые будут работать как продолжение человеческих органов чувств и как хранители здоровья путем прогнозирования рисков и условий в динамической среде. Наноструктуры улучшат эффективность солнечных фотовольтаических систем настолько, что будет возможен переход от стационарных солнечных панелей к носимым фотовольтаикам, и от внешнего солнечного света к условиям низкой освещенности внутри помещений. Источники возобновляемой энергии станут частью некоторых электронных систем, увеличивая их автономность.

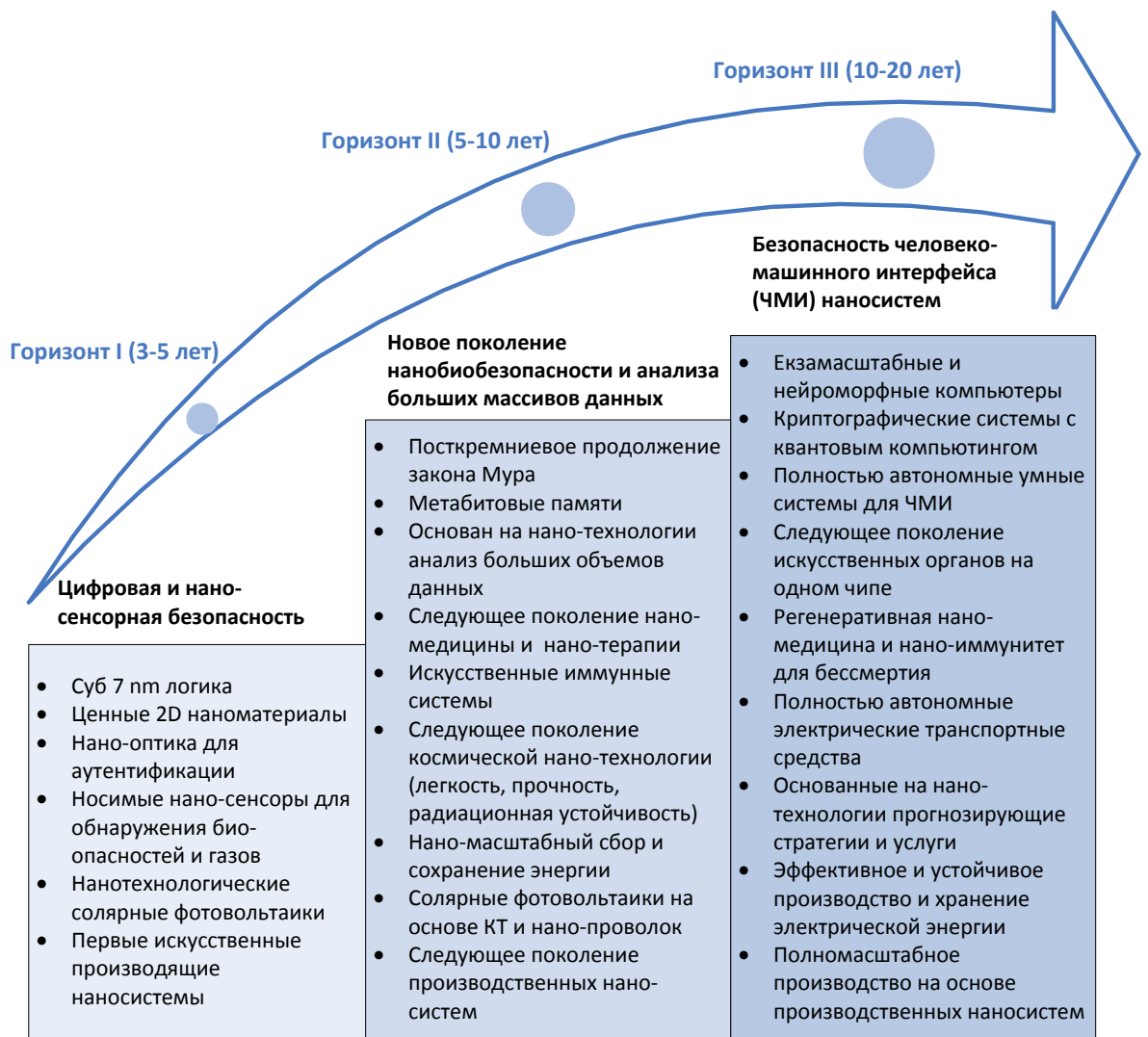

Фигура 3: Дорожная карта сегодняшних и будущих основных тенденций в нанотехнологиях в трех горизонтах, в связи с безопасностью. 
Горизонт II включает следующее поколение систем для нано-биобезопасности и анализа больших массивов данных. После того, как цифровые вычислительные технологии, базирующиеся на архитектурах фон Неймана, достигли границы насыщения в смысле экстремального масштабирования и энергоэффективности, наступит посткремниевая эпоха новых наноматериалов в 3D форме многофункциональных электронных чипов, причем многие из них будут иметь не только вычислительные (логика и память) функции, но и такие характеристики, как встроенные элементы для хранения энергии и аналоговые сенсоры. Технологии цифровой памяти дадут возможность электронике выполнить высокие требования к хранению информации, и в результате большие массивы данных начнут доминировать способы использования приложений и сервисов. Это создаст огромные возможности как для гражданских, так и для связанных с безопасностью приложений, поскольку сети датчиков будут широко применяться в сценариях умного города и при реализации экологических стратегий. Сети (нано) датчиков станут ключевой частью стратегии поля боя, наряду с более умными дронами и методами визуализации для обеспечения полноценной динамической карты враждебного окружения и создания прогнозирующих логик с использованием больших массивов данных. В этот период времени мы увидим появление наномедицины и массовое использование нанотерапии для лечения рака и других болезней. Возможность контролировать, манипулировать и создавать искусственные системы на наноуровне расширит границы медицины, но в то же время породит необходимость в создании нормативной базы и подходов обеспечения безопасности от нано-био рисков не только на поле боя, но и для предотвращения террористических нападений всяческого типа, которые в состоянии оказать влияние на большие массы населения. Обеспечиваемый нанотехнологиями менеджмент энергии на всех уровнях и производственные наносистемы в этот период станут чем-то обычным, и передовые государства начнут осуществлять новые стратегии использования ископаемого топлива и транспорта для обеспечения устойчивого развития.

Горизонт III, называемый безопасность человеко-машинного интерфейса (ЧМИ) нано-систем, касается долгосрочной концепции, характеризуемой экзафлопсным масштабом возможностей компьютинга энергоэффективным нейроморфным и квантовым компьютингом для надежного шифрования и коммуникаций. В медицине основанные на нанотехнологиях регенеративные методы будут использоваться для продления и улучшения качества жизни намного больше, чем сейчас можно себе представить. Общество будет пользоваться полностью автономными и кибер-физическими системами в каждой сфере жизнедеятельности. Благодаря нано-технологиям чМИ достигнет степени совершенства, превышающей все человеческие возможности. Зависимость общества от ископаемого топлива исчезнет, и общество трансформируется в чистую и устойчивую цивилизацию, которая рассчитывает на умные электрические транспортные средства. В наиболее 
оптимистическом сценарии человечество научится как использовать информационные технологии и нано-технологии для распространения демократии и обеспечения нового качества жизни. Сфера медицины станет полностью устойчивой, будет осуществляться прогностическое и персонализированное лечение. Большие массивы данных, полученные с помощью передовых автономных мультипараметрических систем с встроенными функциями самовосстановления и последовательного анализа данных обеспечат оптимизацию промышленных процессов. В энергоэффективном обществе с улучшенным уровнем безопасности угрозы можно будет предвидеть, а не только наблюдать за ними. Военные стратегии для потенциальных конфликтов подвергнутся драматическим переменам, начиная от использования неуязвимых универсальных солдат и дронов, применяющих нанотехнологии для усовершенствования традиционных действий, и заканчивая полностью новыми стратегиями поля боля, с помощью которых множество действий и противодействий и их последствия можно будет предвидеть и оценивать с большой степенью точности.

\section{Последствия для политики и безопасности}

В период после Холодной войны глобальный политический контекст стал очень сложным: развитие глобализации и экономической мощи Азии, увеличение и старение глобального населения, проблемы климата и ресурсов, проблемы устойчивого развития систем здравоохранения в развитых промышленных странах и угрозы безопасности, связанные с терроризмом. В прошлом технологии были слугами политики; сегодня налицо огромные перемены из-за экономического роста и улучшения благосостояния. Политика и конфликты сильно зависят от технологий, которые оказывают существенное влияние на политические решения, начиная с самых ранних этапов. В некоторых случаях это можно рассматривать как соревнование в отношении степени, в которой развитый мир инвестирует в исследования и развитие нанотехнологий. Хотя кое-кем такие инвестиции рассматриваются как отклонение государственных ресурсов от социальных программ для «напрасного» финансирования современных исследований по развитию технологий, такая позиция не оценивает объективно долгосрочные пользы для человечества, даже если и небольшая часть приложений нано-технологий достигнет степени зрелости.

Исследования в Европейском Союзе проводятся в соответствии с «интегрированным, надежным и ответственным» подходом к нанотехнологиям. ${ }^{19}$ Это касается не только нано-материалов, нано-инжиниринга для производственных систем, нано-систем и нано-медицину, но и специального финансирования нано-токсилогических работ и деятельности, связанной с изучением этических аспектов нано-технологий с учетом потенциальных

19 European Commission, Nanotechnology: The Invisible Giant Tackling Europe's Future Challenges (Luxembourg: Publication Office of the European Union, 2013). 
неблагоприятных последствий для человеческого здоровья и окружающей среды. Такой опережающий подход, основанный на оценке пользы и рисков нанотехнологий, очень полезен, и в Европе рассматривается как базис для более широкой нормативной работы на общеевропейском уровне.

Во время разговора в Калифорнийском институте технологий в 2000 году Президент Билл Клинтон продемонстрировал глубокое политическое понимание важности связанных с нано-технологиями последствий для реальной жизни в долгосрочном плане, выдвинув аргументы, которые выглядели как политическое продолжение концептуальной научной речи Ричарда Фейнмана. Клинтон обрисовал цели в области нано-технологий, поддерживаемые национальной политикой:

Только представьте себе, материалы, которые в 10 раз прочнее стали и весящие в несколько раз меньше; сжатие всей информации Библиотеки Конгресса в устройстве размером в кусочек сахара; идентификация раковых опухолей размером всего в несколько клеток. Достижение некоторых из этих исследовательских целей займет более 20 лет. Но именно потому - как раз потому - как сказал доктор Балтимор, так критически важна в этом деле роль государства. ${ }^{20}$

Основания и долгосрочные концепции, изложенные в этой речи, остаются действующими до нынешнего дня.

И последнее, если и есть какая-нибудь прогнозируемая угроза безопасности или угроза конфликта, проистекающая из соперничества между экспансией человека и ограниченными ресурсами планеты, нано-технологии являются одним из наиболее надежных решений этой проблемы. Если есть хоть какая-то надежда на экономическую устойчивость и на безопасность на глобальном уровне, нано-технологии являются одним из ключевых ответов.

\section{Рекомендации и некоторые соображения в отношении политики по нано-технологиям, направленные на увеличение безопас- ности за счет обеспечиваемых нанотехнологиями приложений}

Рекомендации, предложенные в этом разделе, основываются на взглядах автора в качестве исследователя-теоретика в области нано-технологий и нано-электроники, а не человека, имеющего инженерную подготовку.

Рекомендация 1: Как использовать нано-технологии для конкретного нахождения решений глобальных вызовов - здоровье, энергия, изменения климата и безопасность. Нанотехнологии располагают уникальным потенциалом для разрешения глобальных проблем, но часто этот потенциал используется не полностью. Учитывая разнообразие нано-технологических областей, для настоящего прорывного их успеха в разумном временном ин-

20 President Clinton's Address to CalTech on Science and Technology, The White House, Office of the Press Secretary (Los Angeles, CA, 21 January 2000), р. 3, доступно на http://caltechcampuspubs.library.caltech.edu/2676/1/nano_clinton.pdf. 
тервале рекомендуется структурировать подход к исследованиям и разработкам (НИОКР) как целенаправленное сочетание между стратегией "сверху-вниз» (ориентированной на решение проблем) и стратегией "снизу-вверх" (развитие генерических технологий, создание собственных приложений) и привлекать к участию мультидисциплинарные рабочие группы. Национальные ведомства, принимающие участие в НИОКР, должны понимать, что нано-технологии являются областью, которая не обязательно соответствует традиционной структуре исследовательских субъектов и подходов, а потому требует иного менеджмента научных подходов.

Рекомендация 2: Как сделать беспроводные сети датчиков и анализ больших массивов данных факторами, которые радикально изменяют ситуацию с безопасностью. В краткосрочном плане, нано-технологии могут обеспечить создание беспроводных сенсорных узлов с многопараметрическими измерениями и с долговременной автономностью. Сети датчиков, которые используют нано-технологии, являются стратегически важными для безопасности, поскольку они создают динамическую картину среды с очень ранним обнаружением опасностей путем анализа больших объемов данных в реальном времени. Для сферы безопасности эти технологии применимы на разных уровнях, начиная от человеческого тела (сети, расположенные на теле) и кончая строениями, городами и окружающей средой. В краткосрочном плане, для доведения этих технологий до функциональной готовности ключевыми характеристиками и приоритетами, на которых надо сконцентрироваться, являются энергоэффективность и масштабируемость. В частности, желательно усовершенствовать технологию, которая трансферирует конкретные программы, использующие большие массивы данных БСД для превенции в сфере безопасности, например превенции террористических нападений. Кроме того, носимые на теле БСД могут обеспечить осуществление оценки медицинского статуса солдат на поле боя для оценки на месте тяжести ранений и подготовки наиболее эффективного лечения.

Рекомендация 3: Как расширить границы медицины с помощью нанотехнологий, главным образом при лечении рака и болезней мозга. В настоящее время есть острая необходимость в персонализированной медицине и создания новых методов лечения с применением молекулярной технологии; потенциал нано-технологий в этой области исключителен, но есть потребность в изменении парадигмы медицинских исследований. Очень полезным было бы использование фокусированного подхода, основанного на дорожных картах и назначении рубежей для создания и внедрения нанотерапии с учетом как выгод, так и потенциальных угроз. Рекомендуется рассмотрение, с точки зрения политики исследований, возможности проведения широкомасштабных работ в двух ключевых направлениях: нано-терапия рака и нано-терапия болезней мозга, две стратегические области с ограниченным набором решений. Изучение и понимание расстройств работы мозга может иметь важные последствия и для сферы безопасности. 
Рекомендация 4: Опережающие работы по нормативному регулированию и нано-безопасности. Согласно европейским стратегиям, создание нормативной базы и опережающие работы в сфере безопасности полезны для изменения ситуации в этой области в целом; это касается как аппаратной части (технологического осуществления), так и слоя больших массивов данных (безопасность данных и конфиденциальность). Рекомендуется работать над созданием такой нормативной базы и проводить опережающие работы по нано-технологиям в сфере безопасности, уже на раннем этапе встраивая нано-этические принципы как высочайший приоритет будущего общества. Этот аспект даже еще более важен, поскольку военные применения нано-технологий уже нельзя рассматривать отдельно от их применений В гражданской жизни. Возможное недобронамеренное использование должно быть хотя бы затронуто в нормативно-правовых актах в связи с общей проблемой адаптации человека к новым технологиям.

Рекомендация 5: Как избежать нано-разделение в качестве ускорителя неравенства, источника напряжения и международных конфликтов. Многие страны стали свидетелями разделения в результате использования ИКТ, которое связано с неравенством в распределении богатств, общество не должно позволять, чтобы эта пропасть была расширена благодаря нано-технологиям, и с течением времени превратилась в источник будущих конфликтов. Поэтому рекомендуется, чтобы высоко индустриальные страны нашли такую политику перехода от пре-нано к пост-нано миру еще на очень ранних этапах развития нано-технологий.

\section{Об авторе}

Адриан Михай Ионеску занимает должность профессора в Швейцарском Федеральном Институте Технологий в Лозанне (ФИТЛ). Он получил степени бакалавра и магистра естественных наук в Политехническом институте Бухареста в 1989 году и степень кандидата наук в Национальном политехническом институте Гренобля в 1997 году. Занимал постоянные должности и был визитирующим преподавателем в LETI-CEA и LPCS-ENSERG, Гренобль, Франция и в Стэндфордском университете. Он директор лаборатории по микро/наноэлектронным устройствам (NANOLAB). Он назначен национальным представителем Швейцарии в Консультативном совете Европейской нано-электронной инициативе (ENIAC) и является членом Научного комитета CATRENE. Доктор Ионеску также является председателем Рабочей группы по новым исследовательским устройствам Европейского отделения ITRS. E-mail: adrian.ionescu@epfl.ch. 